\title{
GOSTO E CLASSE SOCIAL NO INTERIOR DA INDÚSTRIA CULTURAL BRASILEIRA: O CASO DO TELEJORNALISMO POLICIAL
}

\section{Fábio Ricardo dos Anjos Ribeiro ${ }^{1}$}

Resumo: Este trabalho investiga em que medida a noção de "jornalismo popular", corrente no interior do campo jornalístico brasileiro (seja em sua parcela acadêmica, seja na vertente "profissional"), está vinculada à percepção que esses produtores midiáticos, de maneira mais ou menos consciente, têm das recentes transformações na composição da estrutura de classes no país. Para alcançar esse objetivo, parte da análise específica do telejornalismo policial enquanto gênero midiático tipicamente classificado dentro da categoria "jornalismo popular".

Palavras-chave: indústria cultural; telejornalismo policial; jornalismo popular; classe social; mídia - aspectos sociais.

\section{TASTE AND SOCIAL CLASS WITHIN BRASILIAN CULTURAL INDUSTRY: THE POLICE TELEJOURNALISM CASE}

\begin{abstract}
This work investigates the extent to which the notion of "popular journalism", current within the Brazilian journalistic field (whether in its academic or "professional" domain), is linked to the perception that these media producers, more or less consciously, have of the recent transformations in the composition of the class structure in the country. To achieve this goal, it starts from the specific analysis of police telejournalism as a media genre typically classified within the category "popular journalism".
\end{abstract}

Keywords: cultural industry; police telejournalism; popular journalism; social class; media - social aspects.

\section{Introdução}

No decorrer deste artigo discuto alguns elementos característicos do telejornalismo policial no interior da indústria cultural brasileira. Constato o espaço privilegiado ocupado por esse tipo de programa e a consonância de caracteres, percebidos como típicos do formato, com a maior parte da programação atual da TV. Valho-me de informações sobre audiência desses programas - conforme divulgadas pelas próprias emissoras - com o intuito de destacar informações que, no âmbito da emissão, se têm a respeito da composição do público consumidor. Aponto para a

\footnotetext{
${ }^{1}$ Doutorando em Ciências Sociais - Universidade Federal de Juiz de Fora. E-mail: fabiorarib@gmail.com CSOnline - Revista Eletrônica de Ciências Sociais, Juiz de Fora, n. 23 (2017), pp. 161-176.
} 
posição do jornalismo policial em relação ao jornalismo "de referência", tradicionalmente tido por legítimo no campo. Tomo como casos exemplares, para fins argumentativos, Brasil Urgente (Rede Bandeirantes) e Cidade Alerta (Rede Record), os dois programas de maior audiência da televisão brasileira, hoje, e os jornalísticos de maior duração em quase todos os dias da semana ${ }^{2}$.

Discutirei a noção de "jornalismo popular", a fim de captar a apreensão nativa dos produtores do gênero midiático em questão. Parto da ideia de que é importante conhecer aquilo que esses agentes têm em seus horizontes de representação quando produzem determinado tipo de bem simbólico a ser consumido por determinada parcela da população. As representações que informam o âmbito da emissão dependem daquilo que se presume serem os anseios dos receptores e norteiam forma e conteúdo do que será emitido. Compõem uma espécie de "censura antecipada" (BOURDIEU, 1996, p. 65). Nas palavras de Bourdieu,

[...] as condições de recepção antecipadas fazem parte das condições de produção e a antecipação das sanções do mercado contribui para determinar a produção do discurso. Essa antecipação, que não tem nada a ver com o cálculo consciente, é o resultado do habitus linguístico que, sendo o produto de uma relação primordial e prolongada com as leis de um certo mercado, tende a funcionar como um sentido da aceitabilidade e do valor prováveis de suas próprias produções linguísticas e das dos outros em seus diferentes mercados. (id., p. 64.).

\section{Telejornalismo policial}

Preliminarmente, a noção de telejornalismo policial de que se lança mão aqui é bastante descritiva e diz respeito a caracteres evidentes da atividade. (Tele)jornalismo policial, para os propósitos deste artigo, é aquele que acompanha a atuação das polícias. Através de contatos pessoais dos jornalistas junto às "instituições da ordem" (CALDEIRA, 2003), as fontes principais de notícias são registros de ocorrências policiais, de ações ostensivas nas ruas e informações sobre andamento de investigações. Esse tipo de fonte oficial, que condiciona a ocorrência de um tipo de matéria, inevitavelmente sobredeterminada pela "versão oficial" (HALL, 1978), está presente em todo o jornalismo, mas no de tipo policial ela é a tônica.

\footnotetext{
${ }^{2}$ De acordo com informações disponíveis nos sites das cinco maiores emissoras de TV brasileiras: Globo, Record, SBT, Band e RedeTV! (informação válida em junho de 2017).

CSOnline - Revista Eletrônica de Ciências Sociais, Juiz de Fora, n. 23 (2017), pp. 161-176.
} 
Valendo-se dessa definição, pode-se dizer que os atuais telejornais policiais que compõem a grade da televisão brasileira têm seus antecessores mais imediatos no rádio. Muitos dos apresentadores desses programas tiveram passagens pelo rádio, onde apresentavam programas que igualmente acompanhavam e reportavam a "ronda" policial. Alguns exemplos de grande sucesso no meio foram os programas de Afanázio Jazadji e Gil Gomes. O primeiro ficou conhecido por sua atuação na Rádio Globo de São Paulo, graças às suas contundentes opiniões, caricaturalmente conservadoras, e pelo tratamento eminentemente moralista do tema da segurança pública. O radialista Gil Gomes caracterizou-se midiaticamente por sua maneira peculiar de reconstituir narrativamente os crimes noticiados, dramatizando em detalhes os eventos a partir de poucas informações disponíveis. Graças a essa habilidade interessante ao meio televisivo, o jornalista teve carreira de imensa repercussão nacional, já na década de 1990, como repórter do influente programa Aqui Agora, no SBT.

Existe certo consenso entre pesquisadores do tema ${ }^{3}$ sobre quais seriam os ancestrais nacionalmente conhecidos dos programas policiais, na mesma linha violência urbana e "utilidade pública": na televisão, além do mencionado Aqui Agora, existiram também os programas O Homem do Sapato Branco ${ }^{4}$ e Aqui E Agora 5 . Já na década de 1990 a recém-criada RedeTV! produziu, valendo-se de formato similar, o seu Repórter Cidadão $^{6}$. Outros programas congêneres foram Cadeia Alborguetti, Cadeia, 190 Urgente, todos esses transmitidos nacionalmente pela TV Gazeta, os dois primeiros comandados por Alborguetti, que também ficou famoso pela enérgica performance, caricaturalmente moralista; o terceiro, apresentado pelo ex-repórter de Alborguetti, Carlos Massa, quem veio a se tornar nacionalmente conhecido pelo apelido Ratinho, ainda atuando na linha de jornalismo-denúncia, neste caso também com forte presença do humor. O precursor mais explícito, que misturava notícias policiais com fofocas sobre celebridades midiáticas (há que se preencher a quota de "entretenimento", também percebida como necessária na composição dos programas) e matérias de “defesa do consumidor", é normalmente apontado como sendo o programa O Povo Na TV, transmitido pela TVS na década de 1980.

\footnotetext{
${ }^{3}$ Cf., p. ex., ADERALDO, 2008; OLIVEIRA, 2007; VARJÃO, 2015.

${ }^{4}$ Transmitido inicialmente em 1966, na TV Cultura, foi adquirido pela Rede Globo na mesma década; extinto, em decorrência da censura às atitudes do apresentador, durante o Regime Militar, e retomado na década de 1980, passou pela TVS - atual SBT -, Record e Bandeirantes.

${ }^{5}$ Transmitido pela TV Tupi, no final da década de 1970, e pela TV Bandeirantes, na década de 1980.

${ }^{6}$ Que foi, na maior parte do tempo que durou, apresentado por Marcelo Rezende, hoje âncora do líder nacional de audiência, Cidade Alerta.

CSOnline - Revista Eletrônica de Ciências Sociais, Juiz de Fora, n. 23 (2017), pp. 161-176.
} 
Comuns a todos esses programas, combinados de diversas formas, estão elementos como o comentário indignado sobre as notícias, a abertura para "denúncias" de telespectadores, o tratamento da vida de celebridades, o humor considerado bufão pelo jornalismo culturalmente dominante, a exibição de imagens das cenas dos crimes e, permeando tudo isso, o moralismo no tratamento das ações "transgressoras", sejam estas os atos criminosos propriamente ditos, sejam os comportamentos de celebridades, ou mesmo o julgamento de ações do poder público tidas por imorais. O destaque a esses e outros elementos é normalmente dado, em literatura pertinente ${ }^{7}$, para definir esses programas como sendo "populares", "popularescos", "policialescos”, “mundo-cão", "grotescos", "sensacionalistas" ou tudo isso ao mesmo tempo, em quase invariável tom desqualificador.

A investigação do telejornalismo policial é importante por possibilitar a compreensão de razões para a reprodução de um formato jornalístico quase onipresente na grade televisiva brasileira. Para além dos exemplos de programas mais explicitamente caracterizados no tipo telejornal policial, observa-se hoje uma disseminação de características estilísticas do formato para os demais telejornais. A despeito da argumentação valorativa do autor, coerente com o lugar do qual ela provêm $^{8}$, creio que não seja exagero afirmarmos, juntamente com VALENTE (in VARJÃO, 2015), que há “certa contaminação dos programas jornalísticos, pelo mesmo tipo de linguagem [dos programas policiais]: discurso autoritário e reprodução de imagens e conteúdos degradantes [...]”. (op. cit.., p. 18).

\section{“Jornalismo popular"}

Na grade da TV comercial aberta, o investimento em programas que combinem esses elementos, percebidos no meio como sendo constitutivos do tipo "popular", é justificado, claro, pelos presumidos interesses da audiência. Nesse sentido, é interessante verificarmos o esforço de caracterizar o que seria o "jornalismo popular". A partir daí, tentarei explicitar essa representação nativa da indústria cultural, levando em consideração o trabalho de definição do fenômeno, e, na sequência, apontarei alguns fundamentos sociais dessa concepção, a qual diz muito sobre o que os jornalistas têm

\footnotetext{
${ }^{7}$ Cf., p. ex., AMARAL, 2011; LANA, 2009; SOBRINHO, 1995; VARJÃO, 2015.

${ }^{8}$ A referência foi extraída de uma cartilha didática elaborada pela ANDI, organização da sociedade civil que tem como uma de suas áreas de atuação a monitoração da infração aos direitos humanos na mídia. CSOnline - Revista Eletrônica de Ciências Sociais, Juiz de Fora, n. 23 (2017), pp. 161-176.
} 
em mente quando fazem o telejornalismo policial. Não se trata aqui, é importante advertir, de propor uma definição alternativa, mas de expor uma definição que me parece ser dominante no campo.

De acordo com Márcia Amaral (2011), autora que nos traz uma perspectiva próxima da prática jornalística, no cenário contemporâneo as "mídias usam como estratégia de sedução do leitor a cobertura da inoperância do poder público, da vida das celebridades e o cotidiano de pessoas comuns" (op. cit.., p. 20). A preocupação do jornalismo brasileiro contemporâneo com esses elementos é definidora para Amaral de um investimento no "jornalismo popular". Em abordagem histórica, a autora detecta, por exemplo, que a realização de sorteios, bem como a abertura para recebimento de "sugestões" dos consumidores é prática corrente em publicações jornalísticas impressas destinadas às "classes populares" desde quando existem essas publicações. Na primeira edição do Última Hora, jornal publicado no Rio de Janeiro, de 1951 a 1964, por exemplo, já se anunciava a instalação de urnas na cidade para apuração de opiniões, denúncias e sugestões de seus leitores. Esse tipo de espaço para canalização de anseios práticos, sejam demandas para solução de problemas ou apenas pedidos de participação por meio de mensagens, é de fato característica marcante dos programas analisados aqui.

Para Marialva Barbosa ([2008?]), mais do que a participação, a característica distintiva desse tipo de jornalismo é o apelo ao "sensacionalismo". De acordo com a autora, uma primeira experiência de larga disseminação do formato no Brasil deu-se nos anos 1920, a partir da criação de um conjunto de jornais com esse viés. Para Barbosa,

\footnotetext{
Desde os anos 1910, as notas sensacionais invadem as páginas das principais publicações, mas será na década de 1920, com o aparecimento de jornais diários dedicados inteiramente a este tipo de conteúdo que as tragédias e sensações passam a ser responsáveis diretas pelo sucesso desses jornais. Abandonando as longas digressões políticas, passam a exibir em manchetes, em páginas em que editam, em profusão, ilustrações e fotografias, os horrores cotidianos. (id., p. 12).
}

O que a autora denomina "horrores cotidianos" são as imagens de pessoas ensanguentadas, anomalias físicas, cenários de acidentes e de demais objetos e eventos que são utilizados por causarem um impacto pela repulsa, nojo, horror, mas ao mesmo tempo despertar a piedade e/ou curiosidade e prenderem a atenção das pessoas. As notícias que se valem dessas imagens, pictórica ou verbalmente, apelariam às sensações do público (id., p. 13). Por isso, Barbosa prefere denominar “jornalismo de sensações” o 
tipo de produto cultural que se vale desse material, sistematicamente, pelo menos desde a década de 1920.

Amaral (2011) não nega essa associação histórica, de resto unânime nas pesquisas sobre os programas policiais, entre "jornalismo popular" e "sensacionalismo". Porém, aponta para uma mudança no formato, detectável mais fortemente a partir da segunda metade da década de 1990. Para a autora, essa mudança envolve a passagem do "sensacionalismo" (notícias de violência, sexo, e demais extraordinariedades, sempre em linguagem acessível a camadas menos escolarizadas da população) à maior ênfase no "serviço", à denúncia, à função do jornal como "porta-voz do povo", "com editoriais contra a corrupção, cobertura de eleições com pregação do voto consciente e prestação de serviços (seções de direitos trabalhistas, saúde e sexo)", vagas de emprego etc. (id., p. 26).

\section{"Classe C" como alvo principal}

O livro de Amaral nos dá uma noção bem explícita do que os jornalistas no geral entendem serem os gostos populares pelos produtos jornalísticos. "Popular", no livro, e como é possível se depreender da observação das grades de programação das emissoras de TV aberta no Brasil, está representado por tudo o que diz respeito às classes econômicas C, D e E. Como a "classe C" tem aparecido aos que produzem para a mídia de massa como o grupo consumidor mais numeroso no país, é para essa parcela da população, com seus presumidos interesses - apreendidos por meio de pesquisas de opinião e em grande medida (re)conhecidos como dados de senso comum dos jornalistas no dia a dia de seu trabalho -, que a programação é elaborada. Um trabalho como esse, que inclusive tem o declarado propósito didático de orientar futuros e atuais jornalistas sobre como fazerem um "jornalismo popular com qualidade" (AMARAL, 2011), é fruto mesmo da constatação no campo da existência desse perfil sociocultural de consumidor e da necessidade de os profissionais do ramo conhecerem esse "novo" público. Parte da viabilidade editorial do livro depende exatamente dessa adequação a uma demanda por conhecimento a respeito da denominada "classe C". Uma mensagem do livro é: trata-se de tornarmo-nos conscientes das especificidades desse tipo de jornalismo, atinentes aos gostos desse público consumidor que agora se tornou a maioria no universo de nossos destinatários reais e potenciais. Trata-se de conhecer os 
gostos dessa classe econômica e a estrutura vigente da fórmula repetida na elaboração do material feito para essa categoria de consumidor, agora target hegemônico.

Mas o problema principal relacionado ao crescimento da participação do “jornalismo popular" no mercado, para Amaral, é normativo: trata-se do abandono, nesse formato mais "vulgar", dos "princípios tradicionais do jornalismo", norteados pelo "compromisso com a verdade", a partir da "submissão da imprensa ao gosto do público". O fantasma que acompanharia a todo tempo o bom "jornalismo popular" é o fato de que

a imprensa popular busca satisfazer os leitores a qualquer custo, pois são bastante volúveis em função do baixo poder aquisitivo e precisam ser conquistados cotidianamente. Os produtos jornalísticos populares precisam mostrar uma conexão com seu público, pois são mais dependentes de um mercado que muda facilmente. (AMARAL, 2011, p. 52).

Pouco interesse do público consumidor pela leitura desinteressada explica as estratégias de convencimento adotadas no âmbito da produção. Explica em grande medida as escolhas de linguagem, estilo e conteúdo "facilitados". De todo modo, a imprensa é também instituição componente da indústria cultural e como tal produz mercadorias a serem consumidas. Trata-se, afinal, de sua razão de ser enquanto atividade comercial. Nesse sentido, ela é sempre submetida à demanda, que, por sua vez, é determinada pelo "gosto" do consumidor. O que incomoda os que lamentam a "perda da qualidade" decorrente das determinações estritas do campo econômico, portanto, talvez sejam as mudanças quantitativas ocorridas no próprio público. $\mathrm{O}$ problema ideológico subliminar ao argumento, me parece, não é a submissão ao "público", assim, indistintamente, como assevera a autora, mas a determinado público, ou, mais especificamente, ao "mau gosto" característico de um público de baixos capitais econômico e cultural relativos.

A definição "jornalismo popular" é útil para descrevermos o fenômeno e para compreendermos uma maneira pela qual se definem no interior do campo elementos do conteúdo e linguagem dos produtos midiáticos. No entanto, descrever o fenômeno e reproduzir uma noção nativa, classificando um produto da indústria cultural a partir de caracteres de distinção cultural, não é suficiente para compreendermos a raiz do fenômeno. Faço referência a esse esforço de definição por acreditar que ele representa um ponto de vista comum no campo, tanto entre pesquisadores-engajados, que refletem sobre "a melhor prática na profissão", como entre aqueles profissionais que têm que CSOnline - Revista Eletrônica de Ciências Sociais, Juiz de Fora, n. 23 (2017), pp. 161-176. 
lidar cotidianamente na definição dos conteúdos, e que, no desempenho desse ofício, carregam no habitus linguístico, incorporado a partir da vivência no campo, determinada expectativa sobre suas audiências.

A partir da leitura do texto da jornalista Márcia Amaral é possível conhecermos uma perspectiva da visão dominante no campo; é possível compreendermos o que os próprios jornalistas - no caso desta autora, trata-se de uma também pesquisadora do jornalismo ${ }^{9}$ - encaram os formatos, caracterizando aquilo que fazem. O texto é sintomático da percepção nativa a respeito das transformações ocorridas no mercado de bens midiáticos com o cenário econômico de aumento do "poder de compra" experimentado por determinada parcela da população em anos recentes. A jornalistapesquisadora enxerga o sintoma e inclusive faz sugestões para a produção de um "jornalismo popular de qualidade", ou seja, algo que ao mesmo tempo atenda a alguns pré-requisitos distintivos do jornalismo de referência (produzido e consumido por pessoas com alto capital cultural relativo) e satisfaça os anseios específicos das "classes populares". No entanto, ela não toca nas prováveis causas. Abaixo, apresentarei elementos que acredito poderem explicar o fenômeno cujos reflexos nos "anseios do público" são detectados por Amaral.

\section{Transformações na composição da audiência}

Uma causa central tem a ver com recente mudança ocorrida no público consumidor desses jornais. Esse público tornou-se mais numeroso, com a ascensão de grande contingente populacional à chamada "classe C". Ao mesmo tempo, passou-se a ter acesso fácil a informações e maiores condições de suprimento da demanda por curiosidades "extraordinárias" através da internet. Têm-se, então, mudanças no volume e composição do público consumidor, bem como na forma de consumo.

Para desenvolver esse argumento, é necessário, inicialmente, atentarmo-nos para a TV enquanto empreendimento comercial:

[...], esse tipo de empresa dá lucro na medida em que 'vende' seus espectadores sob a forma de números: índices e perfis de audiência. Ou seja,

\footnotetext{
${ }^{9}$ No campo jornalístico brasileiro há no geral uma divisão entre aqueles que, dotados de diploma universitário, seguem vida acadêmica de pesquisa e ensino e os que, de posse ou não do diploma, seguem carreiras profissionais nos veículos de mídia privados ou públicos. Parece razoável asseverarmos que a noção dominante no campo seja corrente tanto no universo acadêmico como no "profissional".

CSOnline - Revista Eletrônica de Ciências Sociais, Juiz de Fora, n. 23 (2017), pp. 161-176.
} 
os clientes da TV são os anunciantes, que compram horários e espaços para os anúncios, a partir de critérios como a quantidade de espectadores (medidos pelos índices do Ibope) e sua qualidade, ou seja, o que é denominado potencial de consumo desses espectadores (medidos em termos de classe socioeconômica). Nessa indústria, que trabalha na interface de bens culturais e grandes anunciantes (porque anunciar na televisão é relativamente caro, dada sua alta audiência), os espectadores são percebidos como 'consumidores' [...] e são medidos em termos de idade, sexo e classe socioeconômica. (ALMEIDA, 2015, p. 27.).

Com o aumento quantitativo da "classe C", esta se tornou a principal consumidora da mídia comercial aberta. Consequentemente, toda a programação da TV aberta passou a ser direcionada aos supostos gostos dessa classe econômica. É, portanto, no bojo do crescimento desse mercado consumidor que se pode explicar o interesse por essa programação "popular" e a consequente manutenção do telejornalismo policial na grade, com elevados índices de audiência - o que, afinal de contas, leva as emissoras a continuarem produzindo os programas.

Segundo Heloisa Almeida, a publicidade televisiva nos anos 70, 80 e 90 do século passado foi direcionada majoritariamente às classes econômicas $\mathrm{A}$ e $\mathrm{B}$, o público consumidor por excelência, conforme os critérios classificatórios do mercado publicitário. A partir da segunda metade da década de 1990 - com ênfase crescente nos anos 2000 - no entanto, ocorre uma mudança significativa: as programações das emissoras de TV aberta, que historicamente sempre atingiram um público bem mais amplo que aquele de interesse principal da publicidade, passam a ser produzidas a partir dos supostos gostos de uma nova classe econômica em ascensão. Os produtores televisivos passaram a perceber suas audiências como sendo compostas majoritariamente de "pessoas do povo", por membros da "classe C", até então tratados apenas como consumidores "marginais". A publicidade no veículo, também, como não poderia deixar de ser, passou a ser direcionada em maior quantidade para essa "classe C" (parcela que corresponde também à maior parte dos que assistem à TV aberta no Brasil e que, por isso, consta como público consumidor desse meio de comunicação, de acordo com as pesquisas de audiência ${ }^{10}$ ).

\footnotetext{
${ }^{10}$ Apesar de no momento estarem sendo implantados e cada vez mais utilizados no mercado mecanismos de aferição de consumo do conteúdo televisivo que se dá através da internet, TV por assinatura, antenas parabólicas, sistemas on demand etc., a principal composição dos índices de audiência, sobretudo se levarmos em consideração aqueles valores obtidos pela monitoração em "tempo real", se dá por meio da medição do consumo de TV aberta por radiofrequência (Cf. assunto sendo reportado no meio publicitário, p. ex., em: http:<//www.meioemensagem.com.br/home/midia/2015/09/17/ibope-media-lanca-medicaode-video-on-demand.html $>$. Acesso em: 01 ago. 2017).

CSOnline - Revista Eletrônica de Ciências Sociais, Juiz de Fora, n. 23 (2017), pp. 161-176.
} 
Essa recente transformação no perfil das audiências, cujo reflexo no cardápio da indústria cultural têm sido compreendido no meio como um "fenômeno da programação popular” (LANA, 2009, p. 12), está relacionada, portanto, à recente percepção sobre qual é a classe econômica correspondente ao target majoritário e às possibilidades de interação proporcionadas pela internet. Nesse novo contexto, em que passaram a ser diretrizes no mercado de TV a "participação" dos telespectadores, a "interatividade" e "intimidade", "anônimos e desconhecidos tornaram-se fundamentais" (id., p. 13). Esses valores, percebidos como necessidades da comunicação em um mundo em que a internet tornou possível mesmo aos menos privilegiados em termos de capital econômico (antes indispensável para o acesso à informação), passaram a ser a regra na indústria cultural: a programação tornou-se mais "popular”, portanto.

\section{Nova classe consumidora}

Para compreendermos as condições de possibilidade da atual onipresença na grade da TV aberta dos telejornais policiais é necessário, além de conhecermos a percepção que os produtores televisivos têm dessas mudanças, atentarmo-nos para recentes mudanças na estrutura de classes no Brasil. Isso porque os telejornais policiais são, antes de tudo, produtos pensados para serem consumidos por determinadas fatias de mercado. A essas fatias correspondem padrões de consumo que, por sua vez, estão objetivamente ligados a "preferências" culturais e disponibilidade de recursos econômicos.

A definição da estrutura de classes com a qual trabalham os produtores de telejornais - bem como os dos demais produtos da indústria cultural - é aquela construída no âmbito da publicidade. Trata-se do Critério de Classificação Econômica Brasil $^{11}$, adotado pela Associação Brasileira de Empresas de Pesquisa - ABEP, a forma como a indústria de propagandas e, daí em diante, toda a mídia, estratifica os consumidores de seus bens e serviços no país. O Critério Brasil tem o intuito de ser um modelo de estratificação econômica para o Brasil para fins de segmentação de mercado e audiência. A última atualização no modelo foi feita em 2015, para aplicação a partir de 2016. De acordo com os responsáveis, ele é baseado na Pesquisa de Orçamento Familiar do IBGE e toma como variáveis a posse domiciliar de "itens de conforto"

\footnotetext{
${ }^{11}$ Cf. documento disponível em: < http://www.abep.org/criterio-brasil >. Acesso em: 01 ago. 2017.
} CSOnline - Revista Eletrônica de Ciências Sociais, Juiz de Fora, n. 23 (2017), pp. 161-176. 
(quantidades de banheiros, empregados(as) domésticos(as), automóveis, microcomputador, máquina lavadora de louças, geladeira, freezer, lavadora de roupas, aparelho reprodutor de DVD, forno de micro-ondas, motocicleta e máquina secadora de roupas), o grau de escolaridade do(a) chefe de família e a disponibilidade ou não de água encanada e rua pavimentada. De acordo com a pontuação obtida com base nessas variáveis, estabelecem-se 7 estratos de classe de consumo, representados, em ordem decrescente em relação ao "poder de consumo", pelas letras A, B1, B2, C1, C2, D, E. O Critério norteia a visão que os jornalistas têm sobre quem são seus espectadores e compõe em grande medida essa redução da classe social à classe de consumo disseminada pela mídia e presente no senso comum.

Entender as mudanças recentes pelas quais passaram essa forma de classificação ajuda a compreender as transformações nos produtos midiáticos. É fundamental para compreendermos o espaço dedicado às fórmulas supostamente ao gosto da "classe C". Logo, é fundamental para compreendermos o espaço nas grades das emissoras ocupado pelo telejornalismo policial.

Tem predominado no campo midiático contemporâneo certo discurso otimista em relação à emergência no Brasil de uma "nova classe média" (ALMEIDA, 2015; GROHMANN, 2014). Acompanhada das onipresentes narrativas de superação individual a partir de condições de adversidade, está a perseguida imagem de "um Brasil que deu certo" (GROHMANN, op. cit, p. 158.). Essa concepção otimista tem sua origem nas teses do economista Marcelo Neri ${ }^{12}$ (NERI, 2014), autor que aponta para uma inédita ascensão econômica de parcelas mais baixas na estratificação social a um status mediano de renda - e, consequentemente, de consumo - a partir da década de 2000 (id.). Essa ascensão, também observada nos estratos superiores, estaria sendo, contudo, consideravelmente mais expressiva nas classes baixas. Na metodologia de classificação adotada por NERI, o Brasil teria, em 2014,

em torno de 119 milhões de pessoas na classe $\mathrm{C}$ e 29,5 milhões nas classes AB [...]. De 2003 a 2014, apesar do crescimento populacional em geral, a população absoluta nas classes D e E vai diminuir em 44,6 milhões, caindo para quase metade do seu tamanho inicial [...]. (id., pp. 23-24).

\footnotetext{
${ }^{12}$ Marcelo Neri foi presidente do Instituto de Pesquisa Econômica e Aplicada - IPEA entre 2012 e 2014 e Ministro da Secretaria de Assuntos Estratégicos da Presidência da República, de 2013 a fevereiro de 2015.
}

CSOnline - Revista Eletrônica de Ciências Sociais, Juiz de Fora, n. 23 (2017), pp. 161-176. 
Apesar de as taxas de crescimento das classes econômicas A e B serem proporcionalmente maiores do que a da "classe C" (id., p. 25), em termos populacionais essa última seria hoje de longe a mais numerosa. A ascensão generalizada estaria inclusive, para o autor, diminuindo as desigualdades históricas e tornando o Brasil um país majoritariamente "de classe média"!

Jessé Souza (2012) questiona a abrangência dessa tese e apresenta ponderações a respeito da decorrente euforia em relação ao "protagonismo" dessa "classe social nova e moderna, produto das transformações recentes do capitalismo mundial, que se situa entre a "ralé' 13 e as classes média e alta" (id., p.26), ao defender que classe não se define apenas por renda. Isso porque há "fatores e precondições sociais, emocionais, morais e culturais que constituem a renda diferencial" e que devem ser levados em consideração (id., p. 22). As características definidoras do posicionamento dessa classe no espaço social, a saber, a posse de capital econômico e a de capital cultural, não nos permitem enquadrá-la no mesmo estrato da classe média tradicional. Esta, para o autor, é historicamente detentora de uma condição mais favorável, transmitida por herança há pelo menos uma geração. O economicismo reinante no senso comum, reflexo da hegemonia contemporânea da ideologia liberal - e que explica em parte o sucesso da tese de NERI -, enxerga apenas o lado material das transformações, de modo que é levado a pensar em ascensão social como sendo sinônimo de ascensão econômica, apenas. As transformações que vivenciamos no Brasil contemporâneo, para Souza, são de grande vulto na ordem econômica, mas ainda não promoveram mudanças substantivas para se efetivarem de maneira duradoura em outras esferas.

[...] a visão economicista 'universaliza' os pressupostos da classe média [tradicional] para todas as 'classes inferiores', como se as condições de vida dessas classes fossem as mesmas. (SOUZA, 2012, p. 24).

Diante dessa condição de ascensão social sem os privilégios de capital herdado, o autor prefere a designação "batalhadores" para se referir aos membros dessa nova classe. Os "batalhadores" contemporâneos vivem em condições mais precárias que as da classe média tradicional, pois não contam com benefícios de capital herdados. Ascenderam graças ao real aumento do salário, às políticas de assistência, de ampliação do crédito, mas também através de esforços pessoais, no acúmulo de jornadas de duplo emprego ou de trabalho e estudo. Apesar de terem experimentado elevação da renda em

13 O autor denomina 'ralé' o subproletariado mais desprovido das "precondições sociais, morais e culturais" (SOUZA, 2012, p. 25) que permitem qualquer apropriação de capital cultural e econômico.

CSOnline - Revista Eletrônica de Ciências Sociais, Juiz de Fora, n. 23 (2017), pp. 161-176. 
anos recentes, estão longe de alcançar o superlativo capital econômico das classes altas e dispõem em menor volume do capital cultural, um bem disponível em quantidade caracteristicamente elevada nas classes médias tradicionais (id., p. 50).

De todo modo, a constatação generalizada, seja a de perspectiva economicista, que, por se harmonizar com os interesses intrínsecos da empresa midiática, ganhou rápida repercussão nos veículos de comunicação de massa (GROHMANN, 2014), na publicidade (ALMEIDA, 2015) e, por sua vez, nas representações que passaram a refletir esse discurso também na internet, seja a partir do que pode ser apreendido por essa versão sociológica mais crítica, presente no debate público, é a de que temos uma nova realidade de classes que tornou majoritários gostos e anseios relativamente comuns a determinada parcela da população economicamente interessante à indústria cultural.

\section{A audiência dos telejornais policiais}

Determinados bens de consumo são destinados a determinados "públicos". O monitoramento das ações de publicidade que acompanham os programas Brasil Urgente e Cidade Alerta, seja nos intervalos, seja nas ações de merchandising, nos leva a crer que o investimento publicitário nos programas por segmento de mercado está em consonância com o que as emissoras apresentam como sendo os perfis de suas audiências. Abaixo, apresento tabela composta com informações de audiência que as emissoras divulgam em seus sites, tendo como público alvo possíveis clientes:

Tabela 1: Dados sobre audiência disponíveis em páginas destinadas a anunciantes - sites da Band e Record ${ }^{14}$ (valores percentuais)

\begin{tabular}{|c|c|c|c|c|c|c|c|c|c|c|}
\hline Programa & \multicolumn{2}{|c|}{ Sexo } & \multicolumn{5}{|c|}{ Faixa Etária } & \multicolumn{3}{c|}{ Classe da ABEP } \\
\hline & M & F & $\mathbf{4}$ a 11 & $\mathbf{1 2}$ a 17 & $\mathbf{1 8}$ a 24 & $\mathbf{2 5}$ a 49 & $\mathbf{5 0 +}$ & AB & C & DE \\
\hline BU $^{15}$ & 56 & 44 & 3 & 4 & 6 & 32 & 55 & 25 & 55 & 20 \\
\hline
\end{tabular}

\footnotetext{
${ }^{14}$ Acesso em: 01 ago. 2017.

15 Brasil Urgente: dados sobre audiência nacional, produzidos pelo Ibope, referentes ao período maio a julho de 2016.

CSOnline - Revista Eletrônica de Ciências Sociais, Juiz de Fora, n. 23 (2017), pp. 161-176.
} 


\begin{tabular}{|l|l|l|l|l|l|l|l|l|l|l|}
\hline $\mathbf{C A}^{\mathbf{1 6}}$ & 42 & 58 & 5 & 5 & 7 & 35 & 48 & 22 & 54 & 24 \\
\hline
\end{tabular}

Fontes: http://www.band.uol.com.br/comercial/audiencia.asp; http://www.comercial.rederecord.com.br/upload/produtos/perfil/CIAL.pdf. Acessos em: 01 ago. 2017.

Certamente há variações de audiência em relação a horário (provavelmente expressivas variações, nesse caso, uma vez que os programas em questão chegam a ter mais de três horas de duração), dia da semana, percentagem de televisores ligados na emissora no horário do programa em relação às demais (indicador denominado share), dentre outras metrificações estatísticas à disposição dos produtores da mídia televisiva ${ }^{17}$. De qualquer forma, os dados agrupados na tabela acima são padronizados e correspondem a uma média para os programas, o que é suficiente para os propósitos deste trabalho. Como se pode observar na tabela, os perfis de audiência individual, esperados e divulgados pelas emissoras aos anunciantes, apontam um público de iguais proporções entre gêneros e mais concentrado na faixa etária com mais de 50 anos, de membros da referida "classe C".

$\mathrm{Na}$ apresentação que a Rede Record faz de seu produto Cidade Alerta para os potenciais clientes anunciantes ${ }^{18}$ consta a composição do público, conforme os critérios da ABEP. A audiência seria formada majoritariamente por mulheres (58\%), da faixa etária "maiores de 50 anos", da "classe C". Para o mercado são suficientes esses critérios: gênero, idade e poder de consumo, definido pela disponibilidade e possibilidade estimada de se adquirir determinados bens e serviços, como vimos acima. Para as emissoras responsáveis pelos telejornais policiais importam o gosto das pessoas pelos programas e a consequente capacidade que esses têm de atrair audiência para si mesmos e para outros programas da emissora. Interessa o "potencial de consumo" da audiência dos programas, que é aquilo que será vendido aos anunciantes.

\footnotetext{
${ }^{16}$ Cidade Alerta: dados sobre audiência nacional, produzidos pelo Ibope, referentes a junho de 2017.

${ }^{17}$ Em seus sites, as emissoras informam obter os números de audiência citados na tabela a partir do Media Workstation, software vendido pelo Ibope que, vinculado às bases de dados desse Instituto, gera para seus usuários informações detalhadas sobre audiência, inclusive com levantamentos feitos minuto a minuto. (Fonte: < http://www.ibope.com.br/pt-br/solucoes/consumodosmeios/tv/Documents/MW\%20\%20SAIBA\%20MAIS.pdf >. Acesso em: 01 ago. 2017.)

${ }^{18}$ Fonte: site da Rede Record. Disponível em:

$<$ http://comercial.recordtv.com.br/programacao-nacional/cidade-alerta/informacoes-de-midia/ >. Acesso em: 01 ago. 2017.
} 


\section{Considerações Finais}

É possível acompanharmos a maneira pela qual as recentes transformações na estrutura de classes no Brasil, conforme interpretadas por discurso intelectual capaz de pautar o debate na esfera pública, são apreendidas por aqueles que atuam na prática jornalística e pelos que refletem sobre essa prática. Verificamos a existência de um cenário mais geral de constatação da ascensão social de parcelas pauperizadas da população. Naquilo que repercute na e para a indústria cultural, o aumento do "poder de compra" dessa classe consumidora, aliado às mudanças recentes na maneira de fruição dos produtos culturais, possibilitada pela relativa massificação do acesso à internet, vem sendo percebida como a hegemonia da "classe C". Nesse sentido, os produtos, que passaram a ter esse target preferencial, passaram a ser direcionados para os supostos anseios desse público que agora corresponde à maioria.

A noção de "jornalismo popular", fruto da atividade classificatória interior ao campo jornalístico, e que se estabelece na hierarquia simbólica em oposição ao jornalismo legítimo (de classe média [tradicional, que se difere do que é entendido por "classe média" no discurso otimista vigente] ou de "elite", em oposição ao que seria destinado às classes populares), dá-nos acesso às representações jornalísticas que informam sobre o tipo de gostos e estilos de vida que se esperam serem os da "classe C" e contribui para compreendermos melhor as próprias composições da estrutura e conteúdo da programação hoje frequente no menu da indústria cultural brasileira.

\section{Referências}

ADERALDO, Guilhermo André. Das ruas à tela: a representação da violência na mídia eletrônica. 2008. Dissertação (Mestrado em Antropologia Social)-Instituto de Filosofia e Ciências Humanas, Universidade Estadual de Campinas, Campinas/SP, 2008.

ALMEIDA, Heloisa Buarque. "Classe média” para a indústria cultural. Revista Psicologia USP, São Paulo, v. 26, n. 1, p. 27-36, jan./abr. 2015.

AMARAL, Márcia Franz. Jornalismo Popular. São Paulo: Contexto, 2011.

BARBOSA, Marialva Carlos. Jornalismo no Brasil: dois séculos de história. In:

Memória do Jornalismo Brasileiro. Escola de Comunicação da UFRJ, Rio de Janeiro. [2008?]. Disponível em:

$<$ http://memoriadojornalismo.com.br/upload/imagem_0140603053047.pdf $>$. Acesso em: 01 ago. 2017.

CSOnline - Revista Eletrônica de Ciências Sociais, Juiz de Fora, n. 23 (2017), pp. 161-176. 
BOURDIEU, Pierre. A economia das trocas linguísticas: o que falar quer dizer. São Paulo: Edusp, 1996.

Alegre: Zouk, 2006.

A distinção: crítica social do julgamento. São Paulo: Edusp; Porto

CALDEIRA, Teresa Pires do Rio. Cidade de muros: crime, segregação e cidadania em São Paulo. São Paulo: Editora 34; Edusp, 2003.

HALL, Stuart et al. The social production of news. In: Policing the crisis: mugging, the state, and law and order. London: The Macmillan Press, 1978, p. 53-77.

GROHMANN, Rafael. A midiatização da nova classe média: identidades discursivas na revista IstoÉ Dinheiro. Revista RuMoRes, São Paulo, n. 16, v. 8, p. 146-165. jul./dez. 2014.

LANA, Ligia Campos de Cerqueira. Para além do sensacionalismo. Rio de Janeiro: EPapers, 2009.

NERI, Marcelo. A classe média brasileira. In: Assuntos Estratégicos: social e renda. Secretaria de Assuntos Estratégicos da Presidência da República. Brasília, n. 1, nov. 2014. Disponível em: < http://www.sae.gov.br/imprensa/noticia/destaque/assuntosestrategicos-social-e-renda-a-classe-media-brasileira/ >. Acesso em: 01 ago. 2017.

OLIVEIRA, Danilo Duarte. Jornalismo policial na televisão: gênero e modo de endereçamento dos programas Cidade Alerta, Brasil Urgente e Linha Direta. 2007. Dissertação (Mestrado em Comunicação Social)-Programa de Pós Graduação em Comunicação e Culturas Contemporâneas, Universidade Federal da Bahia, Salvador, 2007.

SOBRINHO, Danilo Angrimani. Espreme que sai sangue: um estudo do sensacionalismo na imprensa. São Paulo: Summus, 1995. (Coleção Novas Buscas em Comunicação, v. 47).

SOUZA, Jessé et al. Os batalhadores brasileiros: nova classe média ou nova classe trabalhadora? 2 ed., rev. e ampl. Belo Horizonte: Editora UFMG, 2012.

VARJÃO, Suzana (Org.). Violações de direitos na mídia brasileira: um conjunto de reflexões sobre como coibir violações de direitos no campo da comunicação de massa. Brasília: ANDI, 2015 (Guia de monitoramento de violações de direitos, v. 2). 